These issues present many challenges for the public health workforce in NSW.

\section{REFERENCES}

1. Evaluation Committee. The National Aboriginal Health Strategy: an evaluation. Sydney: NSW Department of Health, 1994.

2. Australian Bureau of Statistics. The Health and Welfare of Australia's Aboriginal and Torres Strait Islander Peoples. Canberra: AGPS, 1997.

3. Australian Bureau of Statistics. The Health and Welfare of Australia's Aboriginal and Torres Strait Islander Peoples. Canberra: AGPS, 1999.

4. Deeble J, Mathers C, Smith L, Goss J, Webb R and Smith V. Expenditures on Health Services for Aboriginal and Torres Strait Islander People. Canberra: AGPS, 1998. AIHW Catalogue No. HWE 6.
5. NSW Department of Health. Better Practice Guidelines to Improve the Level of Aboriginal and Torres Strait Islander Identification in the NSW Public Health System. Sydney: NSW Department of Health, 2000. State Health Publication No. CSP 980163.

6. NSW Department of Health. Improving Aboriginal and Torres Strait Islander origin information in NSW: Report of a pilot study. Sydney: NSW Department of Health, 2000. State Health Publication No. IMCS 990181.

7. NSW Department of Health. Aboriginal and Torres Strait Islander origin information: an important message for NSW Health Staff (pamphlet). Sydney: NSW Department of Health, 2000. State Health Publication No. IMCS 000059 .

For further information and inquiries regarding the Better Practice Guidelines contact Heather Simon, Contract and Service Performance Branch, NSW Department of Health by phone at (02) 93919434 , or by email at hsimon@doh.health.nsw.gov.au. For the training program and pamphlets contact Peter Williams, Information Management and Clinical Systems, NSW Department of Health by phone at (02) 93929110 , or by email at pwill@doh.health.nsw.gov.au.

\title{
QUALITY OF REPORTING OF ABORIGINALITY TO THE NSW MIDWIVES DATA COLLECTION
}

\section{Lee Taylor and Kim Lim}

Epidemiology and Surveillance Branch NSW Department of Health

This article describes a study that used capture-recapture methods to assess the quality of information on Aboriginality reported to the NSW Midwives Data Collection (MDC).

The NSW Aboriginal Health Strategic Plan states that: 'In order to measure improvements and effectively target funding to programs which will improve the health of Aboriginal people, strategies are required to develop robust performance indicators, improve data collection and improve reporting processes'. ${ }^{1}$ Aboriginality is known to be under-reported on Department of Health data collections in NSW, although it is not known to what extent. Improving the quality of information on Aboriginality in health data collections is an important part of improving the overall quality of information on Aboriginal health in NSW.

The MDC is a population-based surveillance system covering all births in NSW public and private hospitals, as well as homebirths. Births in NSW are required to be reported to the MDC under the NSW Public Health Act
1991. The data are used to monitor trends and variations in mortality and morbidity of mothers and newborns, quality of care and the major risk factors for adverse outcomes for mothers and babies. The MDC encompasses all live births and stillbirths of at least 20 weeks gestation or at least 400 grams birth-weight.

\section{METHODS}

The Aboriginality of the mother, rather than the baby, is reported to the MDC, although mother's Aboriginality is frequently used as a proxy measure for the baby's Aboriginality. Consequently, maternal Aboriginality was used for this analysis.

Aboriginal or Torres Straight Islander mothers were counted as one group in the MDC up to 1997 and as two separate groups thereafter. We were therefore unable to examine trends in the quality of reporting for both these groups. For ease of reference, in this report 'Aboriginal' will be used to refer to both groups combined.

Records of births reported to the MDC were linked to birth registration records of the NSW Registry of Births, Deaths and Marriages for births occurring in the five-year period 1994-98. Records from the two files were matched using a probabilistic linkage software (Automatch). Prior 


\section{TABLE 1}

BIRTHSTO ABORIGINAL MOTHERS BY SOURCE OF BIRTH REPORT, YEAR OF BIRTH AND URBANRURAL HEALTH AREA OF HOSPITAL, NSW 1994-98

\begin{tabular}{|c|c|c|c|c|c|c|}
\hline $\begin{array}{l}\text { Urban/Rura } \\
\text { locality of } \\
\text { hospital/ } \\
\text { Year }\end{array}$ & $\begin{array}{c}\text { MDC } \\
\text { births } \\
\text { No. }\end{array}$ & $\begin{array}{c}\text { RBDM } \\
\text { births } \\
\text { No. }\end{array}$ & $\begin{array}{c}\text { Births } \\
\text { reported } \\
\text { to both } \\
\text { MDC/RBDM } \\
\text { No. }\end{array}$ & $\begin{array}{c}\text { Estimated } \\
\text { Aboriginal } \\
\text { births } \\
\text { No. }\end{array}$ & $\begin{array}{c}\text { Estimated } \\
\text { Aboriginal } \\
\text { births } \\
\text { reported } \\
\%\end{array}$ & $\begin{array}{l}95 \% \text { confidence } \\
\text { interval of estimated } \\
\text { births reported }\end{array}$ \\
\hline \multicolumn{7}{|l|}{ Urban } \\
\hline 1994 & 553 & 665 & 268 & 1371 & 40.3 & $37.7-42.9$ \\
\hline 1995 & 642 & 742 & 345 & 1380 & 46.5 & $43.9-49.2$ \\
\hline 1996 & 593 & 794 & 338 & 1392 & 42.6 & $40.0-45.2$ \\
\hline 1997 & 658 & 1066 & 441 & 1590 & 41.4 & $39.0-43.8$ \\
\hline 1998 & 785 & 1053 & 495 & 1669 & 47.0 & $44.6-49.4$ \\
\hline \multicolumn{7}{|l|}{ Rural } \\
\hline 1994 & 990 & 747 & 561 & 1318 & 75.1 & $72.8-77.4$ \\
\hline 1995 & 1117 & 887 & 689 & 1438 & 77.7 & $75.5-79.8$ \\
\hline 1996 & 1131 & 941 & 679 & 1567 & 72.2 & $70.0-74.4$ \\
\hline 1997 & 1196 & 1011 & 789 & 1532 & 78.0 & $76.0-80.1$ \\
\hline 1998 & 1280 & 901 & 771 & 1496 & 85.6 & $83.8-87.4$ \\
\hline \multicolumn{7}{|l|}{ NSW } \\
\hline 1994 & 1543 & 1412 & 829 & 2628 & 58.7 & $56.8-60.6$ \\
\hline 1995 & 1759 & 1629 & 1034 & 2771 & 63.5 & $61.7-65.3$ \\
\hline 1996 & 1724 & 1735 & 1017 & 2941 & 58.6 & $56.8-60.4$ \\
\hline 1997 & 1854 & 2077 & 1230 & 3130 & 59.2 & $57.5-60.9$ \\
\hline 1998 & 2065 & 1954 & 1266 & 3187 & 64.8 & $63.1-66.5$ \\
\hline Note: & th are & $\begin{array}{l}\text { r rural } \\
\text { Sydne } \\
\text { unter a }\end{array}$ & $\begin{array}{l}\text { rea of Hospit } \\
\text { ern Sydney, V } \\
\text { arra. Home bi }\end{array}$ & $\begin{array}{l}\text { S reported } \\
\text { ern Sydne } \\
\text { are exclud }\end{array}$ & $\begin{array}{l}\text { DC. Urbar } \\
\text { Iorth, Sout }\end{array}$ & $\begin{array}{l}\text { oitals include those in } \\
\text { stern Sydney, South }\end{array}$ \\
\hline Source: Lin & ives & ction ar & stry of Births, & aths and Ma & oirth registr & inata. \\
\hline
\end{tabular}

to matching, residential address and mothers' name were standardised using a standardisation software (Autostan). The overall linkage rate was 96.6 per cent of MDC records (97.8 per cent of birth registration records).

Capture-recapture methods are used to adjust estimates of counts to reflect ascertainment level or undercounting. Capture-recapture was carried out using the method described by McCarty et al. ${ }^{2}$ Analysis was carried out using SAS version 6.12. Analyses concerning geographic location were based on health area of hospital of birth as reported to the MDC. Home births were excluded from the analysis.

\section{RESULTS}

The estimated percentage of births to Aboriginal mothers in NSW, which were reported as Aboriginal in the MDC, rose from 58.7 to 64.8 per cent over the fiveyear period 1994-98 (Table 1, Figure 1). Reporting was better in rural hospitals than urban hospitals: in 1998 47.0 per cent of births to Aboriginal mothers in urban hospitals were reported compared to 85.6 per cent in rural hospitals, though there was a trend towards improved reporting in both urban and rural hospitals.
In 1998, the highest ascertainment rate was in hospitals in the New England Area (93.3 per cent) and the lowest in hospitals in the Northern Sydney Area (15.8 per cent) (Table 2). The number of reported births to Aboriginal mothers in Northern Sydney Area hospitals was small for both the MDC and the Registry of Births, Deaths and Marriages and the estimate of total births for this Area is not very reliable, as indicated by the wide confidence intervals (8.7-23.0 per cent).

Of the nine urban health areas, only three (Central Sydney, Wentworth, and Illawarra) had ascertainment rates of maternal Aboriginality of more than 50 per cent in 1998. All rural areas had ascertainment rates of more than 70 per cent.

\section{DISCUSSION}

In using capture-recapture methods, three conditions need to be met:

- the two systems should be independent;

- all true matches and only matches should be identified;

- all cases identified by the two or more surveillance systems should be true cases that occurred in the 


\section{FIGURE 1}

\section{BIRTHS TO ABORIGINAL MOTHERS BYYEAR OF BIRTH AND URBAN-RURAL}

HEALTH AREA OF HOSPITAL, NSW 1994-98

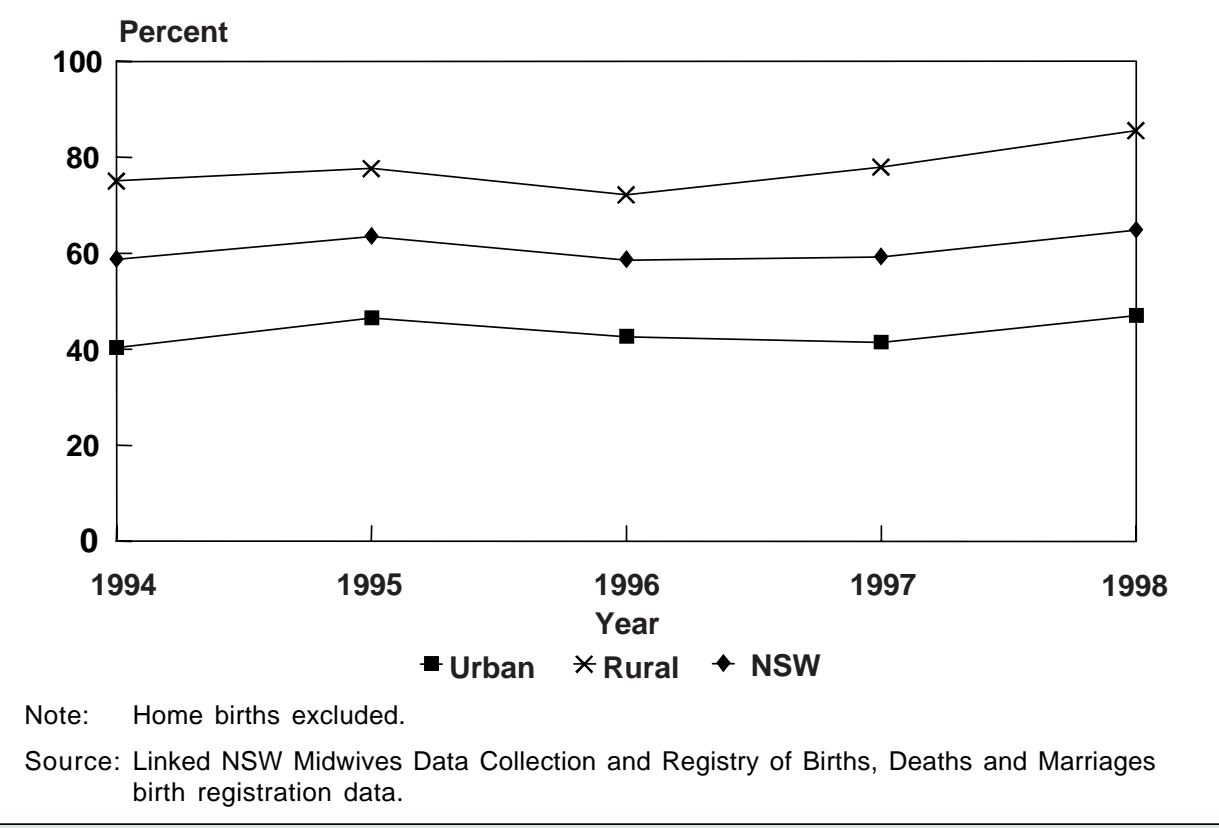

population under investigation and within the appropriate time period. ${ }^{3}$

These three conditions are reasonably well met in this study. First, the two sources of data are independent. Second, the data linkage was carried out in such a way that the likelihood of obtaining true matches was maximised. For the third criteria, it is not known how many mothers in each data collection were incorrectly identified as Aboriginal. It is more likely that mothers would be incorrectly identified as non-Aboriginal than Aboriginal in NSW. If some mothers were incorrectly reported as Aboriginal in either data collection, this study would result in a larger estimate of total births to Aboriginal mothers than is actually the case.

A limitation of this study is that it is restricted to an estimation of the number of births to Aboriginal mothers. Paternal Aboriginality also influences the baby's Aboriginality, and when this is not taken into account the number of Aboriginal babies born in NSW is further underenumerated. For 1998, the linked data set created for this study showed a further 980 births where the father was reported as Aboriginal and the mother was reported as non-Aboriginal both on the MDC and on the birth registration record. Assuming the reporting of paternal Aboriginality on the birth registration record is correct, these 980 births could be added to the 3,187 births to Aboriginal mothers in 1998 , estimated by this study, to give an estimated total of 4,167 births of Aboriginal babies born in NSW in 1998. This is 4.8 per cent of all births in NSW in 1998 and double the 2.4 per cent of births to Aboriginal mothers reported to the MDC in 1998. As for maternal Aboriginality, it is likely that paternal Aboriginality is also under-reported and the true number of Aboriginal babies may be even higher.

In summary, while improvements have been made in the reporting of maternal Aboriginality to the MDC, resulting in a rise from 58.7 to 64.8 per cent of births to Aboriginal mothers being reported as Aboriginal over the five years 1994-98, there is still a need for substantial improvement in reporting of maternal Aboriginality, particularly in urban hospitals. Also, consideration could be given as to whether information on paternal Aboriginality should be obtained from birth registration records on a regular basis and included in reports of the numbers of Aboriginal babies.

\section{REFERENCES}

1. NSW Department of Health. NSW Aboriginal Health Strategic Plan. Sydney: NSW Department of Health, 1999.

2. McCarty DJ, Tull ES, Moy CS, Kwoh CK, LaPorte RE. Ascertainment corrected rates: Applications of CaptureRecapture Methods. Int J Epidemiol 1993; 22(3): 559-565.

3. Desenclos JC, Hubert B. Limitations to the Universal Use of Capture-Recapture Methods. Letter to the editor. Int $J$ Epidemiol 1994; 23(6): 1322-1323. Fit 


\section{TABLE 2}

BIRTHS TO ABORIGINAL MOTHERS BY SOURCE OF BIRTH REPORT, YEAR AND HEALTH AREA OF BIRTH HOSPITAL, NSW 1994-98

\begin{tabular}{|c|c|c|c|c|c|c|}
\hline $\begin{array}{l}\text { Health Area } \\
\text { of hospital/ } \\
\text { Year }\end{array}$ & $\begin{array}{c}\text { MDC } \\
\text { births } \\
\text { No. }\end{array}$ & $\begin{array}{c}\text { RBDM } \\
\text { births } \\
\text { No. }\end{array}$ & $\begin{array}{c}\text { Births } \\
\text { reported } \\
\text { to both } \\
\text { MDC/RBDM } \\
\text { No. }\end{array}$ & $\begin{array}{c}\text { Estimated } \\
\text { Aboriginal } \\
\text { births } \\
\text { No. }\end{array}$ & $\begin{array}{c}\text { Estimated } \\
\text { Aboriginal } \\
\text { births } \\
\text { reported } \\
\%\end{array}$ & $\begin{array}{l}95 \% \text { confidence } \\
\text { interval of estimated } \\
\text { births reported }\end{array}$ \\
\hline \multicolumn{7}{|c|}{ Central Sydney } \\
\hline 1994 & 123 & 84 & 65 & 159 & 77.5 & $71.0-84.0$ \\
\hline 1995 & 113 & 78 & 63 & 140 & 80.9 & $74.4-87.4$ \\
\hline 1996 & 84 & 70 & 51 & 115 & 73.0 & $64.9-81.1$ \\
\hline 1997 & 86 & 101 & 56 & 155 & 55.6 & $47.8-63.4$ \\
\hline 1998 & 73 & 90 & 51 & 129 & 56.8 & $48.2-65.4$ \\
\hline \multicolumn{7}{|c|}{ Northern Sydney } \\
\hline 1994 & 19 & 23 & 11 & 39 & 48.7 & $33.0-64.4$ \\
\hline 1995 & 13 & 24 & 7 & 43 & 30.4 & $16.6-44.2$ \\
\hline 1996 & 13 & 27 & 8 & 43 & 30.5 & $16.7-44.4$ \\
\hline 1997 & 8 & 35 & 6 & 45 & 17.7 & $6.6-28.8$ \\
\hline 1998 & 16 & 29 & 4 & 101 & 15.8 & $8.7-23.0$ \\
\hline \multicolumn{7}{|c|}{ Western Sydney } \\
\hline 1994 & 77 & 93 & 32 & 221 & 34.8 & $28.5-41.1$ \\
\hline 1995 & 85 & 102 & 36 & 238 & 35.7 & $29.6-41.7$ \\
\hline 1996 & 67 & 130 & 42 & 206 & 32.5 & $26.1-38.9$ \\
\hline 1997 & 76 & 144 & 48 & 227 & 33.5 & $27.4-39.6$ \\
\hline 1998 & 127 & 162 & 80 & 257 & 49.5 & $43.4-55.6$ \\
\hline \multicolumn{7}{|l|}{ Wentworth } \\
\hline 1994 & 66 & 73 & 31 & 154 & 42.9 & $35.1-50.7$ \\
\hline 1995 & 82 & 88 & 44 & 163 & 50.3 & $42.6-57.9$ \\
\hline 1996 & 84 & 97 & 40 & 202 & 41.5 & $34.8-48.3$ \\
\hline 1997 & 88 & 140 & 55 & 223 & 39.4 & $33.0-45.9$ \\
\hline 1998 & 131 & 146 & 80 & 239 & 54.9 & $48.6-61.2$ \\
\hline \multicolumn{7}{|c|}{ South Western } \\
\hline 1994 & 76 & 120 & 25 & 357 & 21.3 & $17.0-25.5$ \\
\hline 1995 & 88 & 141 & 52 & 237 & 37.1 & $30.9-43.2$ \\
\hline 1996 & 91 & 142 & 48 & 267 & 34.0 & $28.3-39.7$ \\
\hline 1997 & 84 & 181 & 47 & 321 & 26.1 & $21.3-30.9$ \\
\hline 1998 & 112 & 208 & 63 & 368 & 30.4 & $25.7-35.1$ \\
\hline \multicolumn{7}{|c|}{ Central Coast } \\
\hline 1994 & 15 & 34 & 9 & 55 & 27.3 & $15.5-39.0$ \\
\hline 1995 & 20 & 36 & 12 & 59 & 34.0 & $21.9-46.1$ \\
\hline 1996 & 27 & 48 & 21 & 61 & 44.0 & $31.6-56.4$ \\
\hline 1997 & 36 & 58 & 24 & 86 & 41.7 & $31.3-52.1$ \\
\hline 1998 & 42 & 55 & 24 & 95 & 44.1 & $34.1-54.0$ \\
\hline \multicolumn{7}{|l|}{ Hunter } \\
\hline 1994 & 67 & 101 & 32 & 209 & 32.0 & $25.7-38.4$ \\
\hline 1995 & 94 & 127 & 52 & 228 & 41.1 & $34.8-47.5$ \\
\hline 1996 & 101 & 132 & 56 & 237 & 42.6 & $36.3-48.9$ \\
\hline 1997 & 123 & 183 & 92 & 244 & 50.3 & $44.1-56.6$ \\
\hline 1998 & 111 & 162 & 78 & 230 & 48.2 & $41.8-54.7$ \\
\hline \multicolumn{7}{|l|}{ Illawarra } \\
\hline 1994 & 81 & 78 & 45 & 140 & 57.9 & $49.7-66.1$ \\
\hline 1995 & 112 & 83 & 60 & 155 & 72.4 & $65.4-79.5$ \\
\hline 1996 & 101 & 86 & 59 & 147 & 68.8 & $61.3-76.2$ \\
\hline 1997 & 124 & 122 & 86 & 176 & 70.6 & $63.8-77.3$ \\
\hline 1998 & 113 & 109 & 80 & 154 & 73.5 & $66.5-80.4$ \\
\hline \multicolumn{7}{|c|}{ South Eastern Sydney } \\
\hline 1994 & 29 & 59 & 18 & 94 & 30.9 & $21.6-40.3$ \\
\hline 1995 & 35 & 63 & 19 & 114 & 30.6 & $22.2-39.1$ \\
\hline 1996 & 25 & 62 & 13 & 116 & 21.6 & $14.1-29.0$ \\
\hline 1997 & 33 & 102 & 27 & 124 & 26.6 & $18.8-34.4$ \\
\hline 1998 & 60 & 92 & 35 & 157 & 38.3 & $30.7-45.9$ \\
\hline
\end{tabular}




\section{TABLE 2}

BIRTHS TO ABORIGINAL MOTHERS BY SOURCE OF BIRTH REPORT, YEAR AND HEALTH AREA OF BIRTH HOSPITAL, NSW 1994-98 continued

\begin{tabular}{|c|c|c|c|c|c|c|}
\hline $\begin{array}{l}\text { Health Area } \\
\text { of hospital/ } \\
\text { Year }\end{array}$ & $\begin{array}{c}\text { MDC } \\
\text { births } \\
\text { No. }\end{array}$ & $\begin{array}{c}\text { RBDM } \\
\text { births } \\
\text { No. }\end{array}$ & $\begin{array}{c}\text { Births } \\
\text { reported } \\
\text { to both } \\
\text { MDC/RBDM } \\
\text { No. }\end{array}$ & $\begin{array}{c}\text { Estimated } \\
\begin{array}{c}\text { Aboriginal } \\
\text { births }\end{array} \\
\text { No. }\end{array}$ & $\begin{array}{l}\text { Estimated } \\
\text { Aboriginal } \\
\text { births } \\
\text { reported } \\
\%\end{array}$ & $\begin{array}{c}95 \% \text { confidence } \\
\text { interval of estimated } \\
\text { births reported }\end{array}$ \\
\hline \multicolumn{7}{|c|}{ Northern Rivers } \\
\hline 1994 & 122 & 111 & 74 & 183 & 66.8 & $60.0-73.6$ \\
\hline 1995 & 165 & 120 & 95 & 208 & 79.2 & $73.7-84.7$ \\
\hline 1996 & 143 & 104 & 76 & 195 & 73.2 & $67.0-79.4$ \\
\hline 1997 & 160 & 151 & 111 & 218 & 73.6 & $67.7-79.4$ \\
\hline 1998 & 180 & 131 & 102 & 231 & 77.9 & $72.6-83.3$ \\
\hline \multicolumn{7}{|c|}{ Mid North Coast } \\
\hline 1994 & 141 & 108 & 77 & 197 & 71.4 & $65.1-77.7$ \\
\hline 1995 & 158 & 121 & 92 & 208 & 76.1 & $70.3-81.9$ \\
\hline 1996 & 159 & 135 & 94 & 228 & 69.7 & $63.8-75.7$ \\
\hline 1997 & 174 & 148 & 104 & 247 & 70.4 & $64.7-76.0$ \\
\hline 1998 & 168 & 99 & 82 & 203 & 82.9 & $77.7-88.1$ \\
\hline \multicolumn{7}{|l|}{ New England } \\
\hline 1994 & 199 & 154 & 122 & 251 & 79.3 & $74.3-84.3$ \\
\hline 1995 & 212 & 163 & 144 & 240 & 88.4 & $84.3-92.4$ \\
\hline 1996 & 246 & 178 & 149 & 294 & 83.7 & $79.5-88.0$ \\
\hline 1997 & 267 & 227 & 197 & 308 & 86.8 & $83.0-90.6$ \\
\hline 1998 & 283 & 208 & 194 & 303 & 93.3 & $90.5-96.1$ \\
\hline \multicolumn{7}{|l|}{ Macquarie } \\
\hline 1994 & 193 & 143 & 117 & 236 & 81.9 & $76.9-86.8$ \\
\hline 1995 & 185 & 159 & 114 & 258 & 71.8 & $66.3-77.3$ \\
\hline 1996 & 238 & 210 & 149 & 335 & 71.0 & $66.1-75.9$ \\
\hline 1997 & 261 & 184 & 157 & 306 & 85.4 & $81.4-89.3$ \\
\hline 1998 & 257 & 181 & 164 & 284 & 90.6 & $87.2-94.0$ \\
\hline \multicolumn{7}{|l|}{ Mid Western } \\
\hline 1994 & 100 & 74 & 53 & 139 & 71.8 & $64.3-79.3$ \\
\hline 1995 & 102 & 90 & 64 & 143 & 71.2 & $63.8-78.6$ \\
\hline 1996 & 103 & 111 & 68 & 168 & 61.4 & $54.0-68.7$ \\
\hline 1997 & 93 & 93 & 66 & 131 & 71.1 & $63.3-78.8$ \\
\hline 1998 & 106 & 91 & 67 & 144 & 73.7 & $66.5-80.9$ \\
\hline \multicolumn{7}{|l|}{ Far West } \\
\hline 1994 & 93 & 56 & 51 & 102 & 91.1 & $85.6-96.7$ \\
\hline 1995 & 122 & 77 & 73 & 129 & 94.8 & $91.0-98.7$ \\
\hline 1996 & 76 & 46 & 41 & 85 & 89.2 & $82.7-95.8$ \\
\hline 1997 & 77 & 47 & 39 & 93 & 83.2 & $75.5-90.8$ \\
\hline 1998 & 90 & 52 & 46 & 102 & 88.6 & $82.4-94.8$ \\
\hline \multicolumn{7}{|c|}{ Greater Murray } \\
\hline 1994 & 101 & 72 & 46 & 157 & 64.2 & $56.7-71.6$ \\
\hline 1995 & 107 & 107 & 69 & 166 & 64.6 & $57.3-71.9$ \\
\hline 1996 & 128 & 121 & 83 & 186 & 68.7 & $62.0-75.3$ \\
\hline 1997 & 113 & 118 & 86 & 155 & 72.9 & $65.9-79.9$ \\
\hline 1998 & 132 & 101 & 86 & 155 & 85.2 & $79.6-90.8$ \\
\hline \multicolumn{7}{|l|}{ Southern } \\
\hline 1994 & 41 & 29 & 21 & 56 & 72.9 & $61.2-84.5$ \\
\hline 1995 & 66 & 50 & 38 & 87 & 76.2 & $67.2-85.2$ \\
\hline 1996 & 38 & 36 & 19 & 71 & 53.4 & $41.8-65.0$ \\
\hline 1997 & 51 & 43 & 29 & 75 & 67.8 & $57.2-78.3$ \\
\hline 1998 & 64 & 38 & 30 & 81 & 79.2 & $70.4-88.1$ \\
\hline
\end{tabular}

